\title{
Chronic effects of a high-fat diet enriched with virgin olive oil and a low-fat diet enriched with $\alpha$-linolenic acid on postprandial endothelial function in healthy men
}

\author{
F. Fuentes ${ }^{1,2}$, J. López-Miranda ${ }^{1,2}$, P. Pérez-Martínez ${ }^{1,2}$, Y. Jiménez ${ }^{1,2}$, C. Marín ${ }^{1,2}$, P. Gómez ${ }^{1,2}$, \\ J. M. Fernández ${ }^{1,2}$, J. Caballero ${ }^{3}$, J. Delgado-Lista ${ }^{1,2}$ and F. Pérez-Jiménez ${ }^{1,2}$ \\ ${ }^{1}$ Lipid and Atherosclerosis Unit, Internal Medicine Service, Reina Sofía University Hospital, Avenida Menéndez Pidal s/n, \\ Córdoba 14004, Spain \\ ${ }^{2}$ Ciber Fisiopatología Obesidad y Nutrición (CB06/03) del Instituto de Salud Carlos III, Spain \\ ${ }^{3}$ Biochemistry Service, Reina Sofía University Hospital, Córdoba, Spain
}

(Received 16 May 2007 - Revised 5 November 2007 - Accepted 6 November 2007 - First published online 14 February 2008)

\begin{abstract}
Traditional cardiovascular risk factors are associated with endothelial dysfunction. The vascular endothelium plays a key role in local vascular tone regulation and can be modulated by dietary fat. We propose to determine the chronic effect of three diets with different fat compositions on postprandial endothelial function and inflammatory biomarkers. Twenty healthy men followed three 4-week diets in a randomised cross-over design: a Western diet, rich in saturated fat (22\% SFA, $12 \%$ MUFA and $0.4 \% \alpha$-linolenic acid (ALA), all fractions are \% of energy); a Mediterranean diet, rich in MUFA ( $<10 \%$ SFA, $24 \%$ MUFA and $0.4 \%$ ALA); a low-fat diet enriched in ALA $(<10 \%$ SFA, $12 \%$ MUFA and $2 \%$ ALA). At the end of each dietary period all subjects underwent a postprandial study. Plasma concentrations of lipid parameters, soluble intercellular cell-adhesion molecule-1, soluble vascular cell-adhesion molecule-1 (sVCAM-1), nitrates and nitrites $\left(\mathrm{NO}_{\mathrm{x}}\right)$ and endothelial function studied by laser Doppler were examined at $0,2,4,6$ and $8 \mathrm{~h}$. The endothelium-dependent vasodilatory response was greater $4 \mathrm{~h}$ after the ingestion of the MUFA-rich diet than after the SFA or ALA low-fat diets $(P=0.031)$. The $4 \mathrm{~h}$ postprandial plasma sVCAM-1 levels were lower after the MUFA meals than after the ALA low-fat diet $(P=0.043)$. The bioavailability of $\mathrm{NO}_{\mathrm{x}}$ was higher following the MUFA diet than after the SFA and ALA low-fat diets $(P=0 \cdot 027)$. We found no differences in the other parameters measured. Chronic ingestion of a Mediterranean diet avoids the postprandial deterioration of endothelial function associated with Westernised diets in healthy individuals.
\end{abstract}

Mediterranean diet: Endothelial function: Postprandial state: Adhesion molecules

The vascular endothelium plays a key role in the regulation of local vascular tone. Several authors have pointed out that most traditional cardiovascular risk factors are associated with endothelial dysfunction, and this is regarded as an early marker of $\mathrm{CVD}^{(1)}$. Food intake is an important factor affecting vascular reactivity. Some feeding trials have demonstrated the acute effects of food on improved endothelial function, either as isolated nutrients, such as the phenolic content of virgin olive oil ${ }^{(2)}, n$-3 PUFA ${ }^{(3)}$, L-arginine and antioxidant vitamins, or as a healthy pattern of food intake ${ }^{(4,5)}$. A high-fat meal induces a transitory impairment of endothelial function in association with raised TAG-rich lipoproteins ${ }^{(6)}$. Alteration in vascular reactivity after a fatty meal can be attenuated by pretreatment with antioxidant substances or the addition of antioxidants to the meal ${ }^{(7)}$, suggesting that postprandial oxidative stress plays an important role. This finding supports the theory that many dietary components can regulate the postprandial state, although the underlying mechanism involved is still under debate.
The $n-3$ fatty acids of particular interest for the prevention of CVD include EPA and DHA and are found predominantly in fish and fish oils. $\alpha$-Linolenic acid (ALA), a plant-derived $n-3$ fatty acid and a precursor to EPA and DHA, is also of interest for CVD prevention ${ }^{(8)}$. The biological mechanisms that are postulated to underlie the relationship between $n$-3 fatty acids and the prevention of CVD include decreased arrhythmias, lower TAG concentrations, lower blood pressure and decreased platelet aggregation ${ }^{(9,10)}$. It is still uncertain whether all forms of $n-3$ fatty acids display similar in vivo biological activity and have similar effects on CVD risk ${ }^{(11)}$, and there is no high-quality evidence to support the notion of a beneficial effect of ALA in these questions. However, one plant-derived $n$-3 fatty acid, ALA, has demonstrated a beneficial effect via the induction of a lower level of endothelial activation $^{(12)}$. This issue is analysed in the present study.

The relationship between inflammation and atherosclerosis has been widely studied, and a growing body of evidence suggests that inflammatory processes are intimately involved

Abbreviations: ALA, $\alpha$-linolenic acid; IRH, ischaemic reactive hyperaemia; $\mathrm{NO}_{\mathrm{x}}$, nitrates and nitrites; sICAM-1, soluble intercellular cell-adhesion molecule-1;

sVCAM-1, soluble vascular cell-adhesion molecule-1.

* Corresponding author: Dr Francisco José Fuentes Jiménez, fax +34 957204763, email fjfuentesjimenez@yahoo.es 
in atherogenesis. Several plasma inflammatory markers, including high-sensitive C-reactive protein, soluble intercellular cell-adhesion molecule-1 (sICAM-1) and soluble vascular cell-adhesion molecule-1 (sVCAM-1), can indicate whether individuals are at increased risk of CVD. There are few studies concerning the possible effect of postprandial state on systemic inflammatory activity ${ }^{(13)}$.

Fatty acids from the diet can perform their physiological and cellular functions through their actions on nuclear receptors such as NF- $\mathrm{B}$, which is rapidly activated in response to a variety of inflammatory and other stimuli, such as TNF$\alpha$, oxidised LDL or oxidative stress. Recent data obtained by our group demonstrate that the ingestion of an olive oil meal did not elicit higher levels of NF- $\mathrm{KB}$ activation in mononuclear cells from peripheral blood than ingestion of either a butter- or walnut-rich meal in a postprandial lipaemia study ${ }^{(14)}$. This report describes the effect of an acute intake of a high-fat meal on NF- $\kappa \mathrm{B}$ activation, but the long-term effects of these diets and their repercussions on postprandial inflammatory response are similar, as we also have demonstrated recently ${ }^{(15)}$. Moreover, other recent reports have demonstrated that both palmitic acid and linoleic acid exert inhibitory effect on endothelial NO synthase activation in endothelial cells, which suggests that fatty acids may contribute to $\mathrm{CVD}^{(16)}$.

Insufficient information is available about the postprandial inflammatory and endothelial function response to diets containing different quantities and qualities of fat. The purpose of the present study was to analyse the long-term and background effect of three dietary models with different fatty acid compositions (saturated, monounsaturated and polyunsaturated $n-3$ ) on postprandial endothelial function and adhesion molecules from endothelial cells.

\section{Methods}

\section{Subjects}

Twenty male medical students ranging in age from 18 to 30 years gave their informed consent and submitted to a comprehensive medical history, physical examination, and clinical chemistry analysis before enrolment. The group underwent phenotype testing for apo E, with the object of selecting subjects who presented the phenotype most widespread in the general population (E3E3), thus eliminating the effect triggered by this genetic variation on both postprandial lipaemic response and plasma lipid levels.

Subjects showed no evidence of any chronic disease (hepatic, renal, thyroid or cardiac dysfunction), obesity, or unusually high levels of physical activity (for example, sports training). None of the subjects had a family history of premature coronary artery disease or had taken medications or vitamin supplements in the 6 months before the study. Physical activity and diet, including alcohol consumption, were recorded in a personal $\log$ for 1 week, and the data were used to calculate individual energy requirements. Subjects were encouraged to maintain their regular physical activity and lifestyle and were asked to record in a diary any event that could affect the outcome of the study, such as stress, change in smoking habits and alcohol consumption, or intake of foods not included in the experiment. The study protocol was approved by the Human Investigation Review Committee of the Reina Sofía University Hospital.

\section{Study design}

All subjects were given three isoenergetic diets for periods of $28 \mathrm{~d}$ in a randomised cross-over Latin-square design, as illustrated in 1. Each subject consumed an SFA-enriched diet (SFA diet) $(38 \%$ fat, with $22 \%$ SFA, $12 \%$ MUFA, $4 \%$ PUFA and $0.4 \%$ ALA; $15 \%$ proteins and $47 \%$ carbohydrates); a MUFA-enriched diet (MUFA diet) based on extra-virgin olive oil (38\% fat, with $<10 \%$ SFA, $24 \%$ MUFA, $4 \%$ PUFA and $0.4 \%$ ALA; $15 \%$ proteins and $47 \%$ carbohydrates); a low-fat $n$-3-enriched diet based on ALA from walnuts (Junglans regia L.) $(<30 \%$ fat, with $<10 \%$ SFA, $12 \%$ MUFA, $8 \%$ PUFA and $2 \%$ ALA; $15 \%$ proteins and $55 \%$ carbohydrates). At the end of each dietary period all subjects underwent a postprandial lipaemia study in which they consumed meals with the same fat content ( $1 \mathrm{~g} \mathrm{fat} / \mathrm{kg}$ body weight, $7 \mathrm{mg}$ cholesterol $/ \mathrm{kg}$ and 40 retinol equivalents/kg body weight), and with the same fatty acid compositions as in the design shown in Table 1. After fasting for $12 \mathrm{~h}$, at time 0 , the subjects were provided with a fatty meal consisting of $50-66 \%$ of their daily normal intake of energy. The meals provided $60 \%$ fat, $15 \%$ protein and $25 \%$ carbohydrates. The fat composition of the foods used in the postprandial lipaemia studies was as follows: fatty food based on extra-virgin olive oil (olive oil meal: $22 \%$ SFA, $38 \%$ MUFA, $4 \%$ PUFA and $0.7 \%$ ALA); fatty food based on butter (butter meal: $35 \%$ SFA, $22 \%$ MUFA, $4 \%$ PUFA and $0.7 \%$ ALA); fatty food based on walnuts (walnut meal: $20 \%$ SFA, $24 \%$ MUFA, $16 \%$ PUFA and $4 \%$ ALA). Venous blood samples were collected in tubes containing EDTA $(1 \mathrm{mg} / \mathrm{ml})$, 2, 4, 6 and $8 \mathrm{~h}$ after fatty food intake for the postprandial lipaemia studies at each time point.

The composition of the experimental diets was calculated using United States Department of Agriculture ${ }^{(17)}$ food tables and Spanish food composition tables for local foodstuffs ${ }^{(18)}$. All meals were prepared in the hospital kitchen and were supervised by a dietitian. Lunch and dinner were eaten in the hospital dining room, while breakfast and an afternoon snack were eaten in the medical school cafeteria. Fourteen menus were prepared with regular solid foods and were rotated during the experimental period. Duplicate samples from each menu were collected, homogenised, and stored at $-70^{\circ} \mathrm{C}$. The protein, fat and carbohydrate contents of the diet were analysed by standard methods ${ }^{(19)}$. Dietary compliance was

Table 1. Intervention dietary study design

\begin{tabular}{|c|c|c|c|}
\hline & Group 1 & Group 2 & Group 3 \\
\hline Weeks 0-4 & SFA diet & MUFA diet & $\begin{array}{l}\text { ALA-enriched } \\
\text { and low fat-diet }\end{array}$ \\
\hline Weeks 4-8 & MUFA diet & $\begin{array}{l}\text { ALA-enriched } \\
\text { and low-fat } \\
\text { diet }\end{array}$ & SFA diet \\
\hline Weeks 8-12 & $\begin{array}{l}\text { ALA-enriched } \\
\text { and low-fat } \\
\text { diet }\end{array}$ & SFA diet & MUFA diet \\
\hline
\end{tabular}

ALA, $\alpha$-linolenic acid. 
verified by analysing the fatty acids in LDL-cholesteryl esters at the end of each dietary period by the Ruiz-Gutierrez $\operatorname{method}^{(20)}$. The study took place during January and March in order to minimise seasonal effects and academic stress.

\section{Lipid analysis and biochemical determinations}

Venous blood was extracted after a $12 \mathrm{~h}$ fast, and at 120, 240 and $360 \mathrm{~min}$ after consumption of the fat meal. The samples were collected in tubes containing EDTA $(1 \mathrm{~g} / \mathrm{l})$ or $3.8 \%$ citrate, and were stored in containers with ice. A similar procedure was used for the different determinations of the samples in all the other periods avoiding exposure to air, light and deviations from room temperature. Plasma was obtained by low-speed centrifugation at $1500 \mathrm{~g}$ for $15 \mathrm{~min}$ at $4^{\circ} \mathrm{C}$, within $1 \mathrm{~h}$ of extraction. Lipid parameters were assessed with the modular autoanalyser DDPPII Hitachi (Roche, Basel, Switzerland), using specific reagents (Boehringer-Mannheim, Mannheim, Germany). Total cholesterol and TAG levels were determined by colorimetric enzymic methods. HDL-cholesterol levels were measured using a colorimetric assay after precipitating the lipoproteins containing apo B with polyethylene glycol. LDL-cholesterol levels were estimated using the Friedewald formula based on the total cholesterol, TAG and HDL-cholesterol values. In order to determine nitrates and nitrites $\left(\mathrm{NO}_{\mathrm{x}}\right)$, the plasma samples were ultracentrifuged using the Microcon Centrifugal Filter Device YM-10 (Millipore, Billerica, MA, USA). The filters were pre-rinsed with UltraPure water before ultrafiltration of plasma in order to reduce background absorbance due to the presence of $\mathrm{Hb}$. A $40 \mu \mathrm{l}$ sample of the filtrate was used for the $\mathrm{NO}_{\mathrm{x}}$ assay, using the nitrate/nitrite colorimetric kit (Cayman-Chemical Company, Ann Arbor, MI, USA). Plasma concentrations of sICAM-1 and sVCAM-1 were determined in duplicate with commercially available ELISA kits (R\&D Systems, Minneapolis, MN, USA). Each assay was calibrated with SVCAM-1 and sICAM-1 standard curves. The minimum detectable levels of sVCAM-1 and sICAM-1 were 0.17 and $0.35 \mathrm{ng} / \mathrm{ml}$ respectively. Intra-assay and inter-assay $\mathrm{CV}$ were $3 \cdot 1$ and $7 \%$, respectively.

\section{Endothelial function}

Laser-Doppler linear Periflux 5000 (Perimed S.A., Stockholm, Sweden) was used to measure ischaemic reactive hyperaemia (IRH). With the patient lying in the supine position in a room at stable temperature $\left(20-22^{\circ} \mathrm{C}\right)$, the blood pressure cuff (HG Erkameter 300; Erka, Bad Tolz, Germany) was placed $5 \mathrm{~cm}$ above the elbow, while the laser probe was attached to the palmar surface of the second finger of the same dominant hand. After a 5 min resting period, basal capillary flow was measured for $1 \mathrm{~min}(\mathrm{t} 0)$, after which $4 \mathrm{~min}$ distal ischaemia was induced by inflating the cuff to suprasystolic pressure $(200-220 \mathrm{mmHg})$. The cuff was then deflated and, after $30 \mathrm{~s}$, the flow was recorded for $1 \mathrm{~min}(\mathrm{td})$. The data were recorded and stored using PeriSoft for Windows. The values of the area under the curve (AUC) of the t0 and td times were analysed. These data were used to calculate the increase in post-ischaemic flow by means of the formula: $\mathrm{IRH}=\left(\mathrm{AUC}_{\mathrm{td}}-\mathrm{AUC}_{\mathrm{t} 0}\right) \times 100 \mathrm{AUC}_{\mathrm{t} 0}$. This calculation was carried out using the basal determinations, and at 2, 4, 6 and $8 \mathrm{~h}$ after the consumption of each fatty meal.

\section{Statistical analysis}

All data, except TAG, were normally distributed. To test the normality of variables we used the Shapiro-Wilk test. Several variables were calculated to define the postprandial response of lipid parameters in plasma. The data were analysed using Student's $t$ test for paired data and ANOVA for repeated measures. We studied the statistical effects of the type of fat meal ingested, independent of time (represented by P1), the effect of time (represented by $\mathrm{P} 2$ ), and the interaction of both factors, indicative of the degree of the postprandial

Table 2. Fatty acid composition (\% of the total of fatty acids) of cholesteryl esters from low-density lipoprotein at the end of each dietary period and after $3 \mathrm{~h}$ in the postprandial state

(Mean values and standard deviations)

\begin{tabular}{|c|c|c|c|c|c|c|c|c|c|c|c|c|}
\hline \multirow[b]{3}{*}{ Fatty acid } & \multicolumn{6}{|c|}{$\mathrm{Oh}$} & \multicolumn{6}{|c|}{$3 \mathrm{~h}$} \\
\hline & \multicolumn{2}{|c|}{ SFA diet } & \multicolumn{2}{|c|}{ MUFA diet } & \multicolumn{2}{|c|}{$\begin{array}{l}\text { ALA-enriched } \\
\text { low-fat diet }\end{array}$} & \multicolumn{2}{|c|}{ SFA diet } & \multicolumn{2}{|c|}{ MUFA diet } & \multicolumn{2}{|c|}{$\begin{array}{l}\text { ALA-enriched } \\
\text { low-fat diet }\end{array}$} \\
\hline & Mean & SD & Mean & SD & Mean & SD & Mean & SD & Mean & SD & Mean & SD \\
\hline $14: 0$ & $0.53^{*}$ & 0.18 & 0.4 & 0.12 & 0.38 & 0.16 & $1 \cdot 4^{*}$ & 0.43 & 0.3 & 0.15 & 0.4 & 0.15 \\
\hline $16: 0$ & $21 \cdot 95^{\star}$ & 1.4 & $21 \cdot 16$ & 1.54 & $20 \cdot 79$ & 1.04 & $23 \cdot 1^{*}$ & 0.71 & 20.05 & 0.84 & $20 \cdot 10$ & $1 \cdot 38$ \\
\hline $16: 1$ & 0.43 & 0.12 & 0.4 & 0.14 & 0.45 & 0.13 & 0.36 & 0.15 & 0.36 & 0.13 & 0.4 & 0.15 \\
\hline $18: 0$ & 8.98 & 0.96 & $9 \cdot 13$ & 1.01 & $9.41 \dagger$ & 1.08 & $10 \cdot 05^{\star}$ & $1 \cdot 10$ & 8.5 & 0.99 & $8 \cdot 88$ & 1.0 \\
\hline $18: 1$ & $18 \cdot 24$ & $2 \cdot 13$ & $20 \cdot 12 \ddagger$ & $2 \cdot 7$ & $17 \cdot 80$ & 2.42 & $18 \cdot 35$ & $2 \cdot 3$ & $27 \cdot 43 \ddagger$ & 3.98 & $17 \cdot 5$ & $1 \cdot 21$ \\
\hline $18: 2$ & 23.30 & $2 \cdot 15$ & 22.00 & 2.9 & $25.90 \dagger$ & 1.64 & $23 \cdot 10$ & $1 \cdot 1$ & 21.90 & $2 \cdot 28$ & $30 \cdot 15 \dagger$ & 1.6 \\
\hline $18: 3$ & 0.34 & 0.7 & 0.35 & 0.08 & 0.41 & 0.15 & 0.38 & 0.12 & 0.38 & 0.04 & $1.88 \dagger$ & 0.63 \\
\hline $20: 4$ & 0.31 & 0.09 & 0.3 & 0.15 & 0.36 & 0.19 & $0.35^{\star}$ & 0.05 & 0.28 & 0.09 & 0.3 & 1.02 \\
\hline $20: 5$ & 0.45 & 0.6 & $0.61 \ddagger$ & 0.9 & 0.55 & 0.11 & 0.43 & 0.8 & $0.53 \ddagger$ & 1.0 & 0.45 & 0.9 \\
\hline $20: 6$ & $2 \cdot 25$ & $1 \cdot 12$ & 2.7 & 0.89 & 2.5 & 0.7 & 2.06 & 0.98 & $2 \cdot 18$ & $1 \cdot 2$ & $2 \cdot 2$ & 1.3 \\
\hline
\end{tabular}

ALA, $\alpha$-linolenic acid.

* Mean value is significantly different from those for the MUFA diet and the ALA-enriched low-fat diet $(P<0.05)$

$\dagger$ Mean value is significantly different from those for the SFA and MUFA diets $(P<0.05)$.

$\ddagger$ Mean value is significantly different from those for the SFA diet and the ALA-enriched low-fat diets $(P<0.05)$. 
Table 3. Baseline characteristics of subjects

(Mean values and standard deviations)

\begin{tabular}{lcc}
\hline & Mean & SD \\
\hline Age (years) & $23 \cdot 3$ & 1.5 \\
BMI (kg/m $\left.{ }^{2}\right)$ & 24.65 & 2.91 \\
Total cholesterol $(\mathrm{mg} / \mathrm{l})$ & 1514.5 & $202 \cdot 9$ \\
LDL-cholesterol $(\mathrm{mg} / \mathrm{l})$ & $843 \cdot 8$ & 199.5 \\
HDL-cholesterol $(\mathrm{mg} / \mathrm{l})$ & 496.5 & 80.9 \\
TAG $(\mathrm{mg} / \mathrm{l})$ & 877 & 387 \\
\hline
\end{tabular}

response in each group of subjects with each fat meal (represented by P3). A value of $P<0.05$ was considered statistically significant. Pearson's linear correlation coefficient was calculated, and a multiple linear regression analysis was carried out. Statistical analysis was performed using SPSS 11.0 for Windows (SPSS Inc., Chicago, IL, USA). All data presented in the text and tables are expressed as mean values and standard deviations.

\section{Results}

The fatty acids in cholesteryl esters from LDL at the end of each dietary period are shown in Table 2, and the subjects' baseline parameters in Table 3. The values of the lipid parameters, the adhesion molecules and the bioavailability of $\mathrm{NO}_{\mathrm{x}}$ at the end of each dietary period are shown in Table 4 . After the ingestion of the SFA diet, plasma levels of total cholesterol and LDLcholesterol were higher than after the MUFA-rich and ALAenriched-low-fat diets. After the MUFA diet, plasma levels of HDL-cholesterol were higher than after the ALA-enrichedlow-fat diet. Plasma levels of sVCAM-1 were lower after the consumption of the MUFA and ALA-enriched-low-fat diets than after the SFA diet. Finally, $\mathrm{NO}_{\mathrm{x}}$ bioavailability was greater after the MUFA diet than following the ALA-enriched-low-fat diet or the SFA diet.

The lipid profiles of the three postprandial lipaemias at different times are shown in Table 5. The analysis reveals significant differences in TAG levels between the postprandial responses to each of the dietary models, in that the postprandial lipaemic response in terms of TAG levels was higher $2 \mathrm{~h}$ after the MUFA-rich diet than after the two other diets, while its subsequent clearance was more rapid after this diet than after the two other diets. We found no differences in any of the other lipid parameters.

Levels of sVCAM-1 displayed a larger fall $4 \mathrm{~h}$ after the MUFA and SFA diets than the ALA-enriched-low-fat diet $(-100$ and $-136 v .-9 \mathrm{ng} / \mathrm{ml} ; P=0.043)$. This response was also found, but to a lesser degree, $6 \mathrm{~h}$ after ingestion of the SFA diet than after the ALA-enriched-low-fat diet $(-112 v$. $-2 \mathrm{ng} / \mathrm{ml} ; P=0.041$ ) (Fig. 1). No significant differences in postprandial sICAM-1 response were observed (Fig. 2).

In the study of endothelial function, the ingestion of the butter meal induced a decrease in the postprandial IRH while the ingestion of the olive oil meal did not reduce the IRH during the postprandial period. The postprandial vasodilatory response was lower following the meals rich in saturated fat and the low-fat and ALA-enriched meals than after the MUFA diet at $4 \mathrm{~h}(P=0.031)$ and at $6 \mathrm{~h}(P=0.013)$ (Fig. 3).

Finally, we found a significant positive correlation between the bioavailability of $\mathrm{NO}_{\mathrm{x}}$ and IRH after the MUFA-rich diet, both at baseline and after $4 \mathrm{~h}(r 0.411, P=0.042 ; r 0.439$, $P=0.021$, respectively) and we found no correlations between other parameters at the other time points (Table 6).

\section{Discussion}

The present study demonstrates that long-term ingestion over 4 weeks of a diet containing a large proportion of a component rich in monounsaturated fat, such as olive oil, avoids the deterioration of postprandial endothelial function associated with fatty foods in healthy individuals. This finding is also supported by the higher bioavailability of $\mathrm{NO}_{\mathrm{x}}$ after the ingestion of this diet and by an improvement in the endothelium-mediated vasodilatory response, compared with the postprandial responses induced by the SFA and ALA-enriched low-fat diets.

Unlike the findings of other studies that have analysed postprandial endothelial function following the ingestion of particular diets in acute regimens ${ }^{(2,3)}$, the effects found by the present study were the results of the consumption of diets over a period of 4 weeks. Chronic ingestion results in a

Table 4. Basal study at the end of each dietary period* (Mean values and standard deviations)

\begin{tabular}{|c|c|c|c|c|c|c|c|}
\hline & \multicolumn{2}{|c|}{ SFA diet } & \multicolumn{2}{|c|}{ MUFA diet } & \multicolumn{2}{|c|}{$\begin{array}{l}\text { ALA-enriched } \\
\text { low-fat diet }\end{array}$} & \multirow[b]{2}{*}{$P$} \\
\hline & Mean & SD & Mean & SD & Mean & SD & \\
\hline Total cholesterol (mg/l) & $1480 \dagger$ & 200 & 1390 & 210 & 1370 & 240 & 0.035 \\
\hline TAG $(\mathrm{mg} / \mathrm{l})$ & 800 & 420 & 800 & 420 & 770 & 350 & 0.570 \\
\hline HDL-cholesterol (mg/l) & 450 & 80 & $450 \ddagger$ & 70 & 430 & 70 & 0.029 \\
\hline LDL-cholesterol (mg/l) & $860 †$ & 200 & 780 & 180 & 780 & 210 & 0.034 \\
\hline sVCAM-1 (ng/ml) & $701 \dagger$ & 69 & 512 & 38 & 487 & 48 & 0.017 \\
\hline sICAM-1 (ng/ml) & 332 & 14 & 278 & 10 & 310 & 18 & 0.080 \\
\hline $\mathrm{NO}_{\mathrm{x}}(\mu \mathrm{m})$ & $4 \cdot 2$ & 0.3 & $5 \cdot 2^{\ddagger \S}$ & 0.5 & $3 \cdot 7$ & 0.3 & 0.027 \\
\hline
\end{tabular}

ALA, $\alpha$-linolenic acid; sVCAM-1, soluble vascular cell-adhesion molecule-1; sICAM-1, soluble intercellular cell-adhesion molecule-1; $\mathrm{NO}_{x}$, nitrates and nitrites.

* Data were analysed using ANOVA for repeated measures.

† Mean value is significantly greater than those for the MUFA diet and the ALA-enriched low-fat diet $(P<0.05)$.

$\ddagger$ Mean value is significantly greater than that for the ALA-enriched low-fat diet $(P<0.05)$.

$\S$ Mean value is significantly greater than that for the SFA diet $(P<0.05)$ 
Table 5. Postprandial lipid parameters after each dietary period $\left(\mathrm{mg} / \mathrm{l}^{*}\right.$

(Mean values and standard deviations)

\begin{tabular}{|c|c|c|c|c|c|c|c|c|}
\hline \multirow[b]{2}{*}{ Time and meal } & \multicolumn{2}{|c|}{ Total cholesterol } & \multicolumn{2}{|c|}{ TAG } & \multicolumn{2}{|c|}{ HDL-cholesterol } & \multicolumn{2}{|c|}{ LDL-cholesterol } \\
\hline & Mean & SD & Mean & SD & Mean & SD & Mean & SD \\
\hline \multicolumn{9}{|l|}{ Baseline } \\
\hline SFA & 1480 & 200 & 800 & 420 & 450 & 80 & 860 & 200 \\
\hline MUFA & 1390 & 210 & 800 & 420 & 450 & 70 & 780 & 180 \\
\hline ALA low-fat & 1370 & 240 & 770 & 350 & 430 & 70 & 780 & 210 \\
\hline \multicolumn{9}{|l|}{$2 \mathrm{~h}$} \\
\hline SFA & 1350 & 240 & 1330 & 600 & 400 & 80 & 680 & 190 \\
\hline MUFA & 1320 & 190 & $1690 \dagger$ & 540 & 390 & 70 & 590 & 210 \\
\hline ALA low-fat & 1300 & 190 & 1240 & 530 & 400 & 80 & 650 & 200 \\
\hline \multicolumn{9}{|l|}{$4 \mathrm{~h}$} \\
\hline SFA & 1390 & 210 & 1240 & 620 & 400 & 70 & 710 & 210 \\
\hline MUFA & 1380 & 210 & 1120 & 620 & 400 & 70 & 650 & 160 \\
\hline ALA low-fat & 1340 & 200 & 1190 & 660 & 420 & 130 & 670 & 210 \\
\hline \multicolumn{9}{|l|}{$6 \mathrm{~h}$} \\
\hline SFA & 1370 & 240 & 1010 & 670 & 400 & 60 & 760 & 220 \\
\hline MUFA & 1350 & 240 & $770 \dagger$ & 550 & 410 & 70 & 780 & 200 \\
\hline ALA low-fat & 1330 & 220 & 960 & 650 & 400 & 90 & 770 & 210 \\
\hline \multicolumn{9}{|l|}{$8 \mathrm{~h}$} \\
\hline SFA & 1480 & 210 & $600 \ddagger$ & 460 & 430 & 130 & 930 & 220 \\
\hline MUFA & 1420 & 240 & $610 \ddagger$ & 480 & 450 & 80 & 850 & 200 \\
\hline ALA low-fat & 1400 & 260 & $590 \ddagger$ & 420 & 440 & 70 & 840 & 190 \\
\hline \multicolumn{9}{|l|}{ Global analysis } \\
\hline Diet effect & \multicolumn{2}{|c|}{0.563} & \multirow{2}{*}{\multicolumn{2}{|c|}{0.949}} & \multirow{2}{*}{\multicolumn{2}{|c|}{0.928}} & \multicolumn{2}{|c|}{0.931} \\
\hline Time effect & \multicolumn{2}{|c|}{0.001} & 0.001 & & & 0.001 & \multicolumn{2}{|c|}{0.001} \\
\hline Diet $\times$ time interaction & \multicolumn{2}{|c|}{0.411} & \multicolumn{2}{|c|}{0.041} & \multicolumn{2}{|c|}{0.554} & \multicolumn{2}{|c|}{0.498} \\
\hline
\end{tabular}

ALA, $\alpha$-linolenic acid

*Data were analysed using ANOVA for repeated measures followed by Tukey's post hoc test.

†For TAG, effects of the MUFA diet differ from those of the SFA diet and the ALA-enriched low-fat diet at 2 and $6 \mathrm{~h}$ post-ingestion $(P<0.05)$

¥For TAG, effects at $8 \mathrm{~h}$ post-ingestion are different from those at other times $(2,4$ and $6 \mathrm{~h})(P<0.05)$.

more faithful translation of the effects of the different dietary models, in that meal consumption is not an isolated phenomenon, and in the type of design that employs only acute ingestion of fats it is impossible to separate out the potential effects of the background diet on the endothelium.

The term 'endothelial dysfunction' implies a loss of homeostasis resulting from a complex interaction of vasodilatory and vasoconstrictive factors, on which diet exercises a crucial influence $^{(21)}$. Several studies have shown that the ingestion of a fat-rich meal induced postprandial endothelial dysfunction $^{(4,22)}$, although such an effect has not been demonstrated

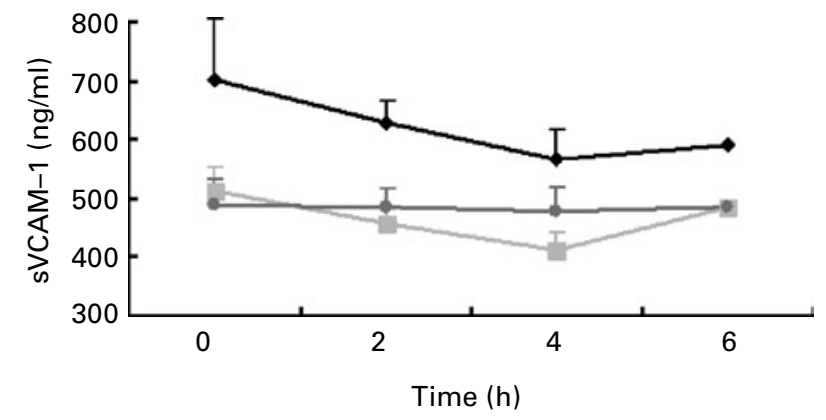

Fig. 1. Soluble vascular cell-adhesion molecule-1 (sVCAM-1) levels in the postprandial state after SFA $(\diamond)$, MUFA $(\square)$ and $\alpha$-linolenic acid (ALA)enriched low-fat $(\square)$ diets. Values are means, with standard deviations represented by vertical bars. Data were analysed using ANOVA for repeated measures. There is a diet effect $(P=0.026)$, a time effect $(P=0.047)$ and a time $\times$ diet interaction $(P=0.046)$. by other studies ${ }^{(2,23)}$. In this respect, our group has already shown that meals enriched with virgin olive oil do not result in activation of the postprandial inflammatory route, in that they diminish oxidative stress after stabilising the NF- $\mathrm{BB}$ system, unlike the action of diets rich in saturated fats ${ }^{(14)}$. Moreover, thanks to their content of antioxidative phenols, diets rich in virgin olive oil are capable of alleviating oxidative stress and other studies have demonstrated an association between virgin olive oil and an improvement in postprandial vascular function ${ }^{(2)}$. In the present study, endothelium-mediated vasodilatation (IRH) was greater following

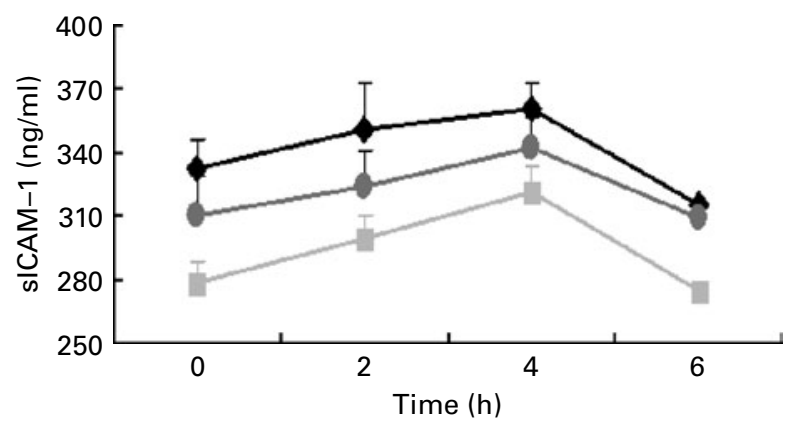

Fig. 2. Soluble intercellular cell-adhesion molecule-1 (sICAM-1) levels in the postprandial state after SFA ( $)$, MUFA $(\square)$ and $\alpha$-linolenic acid (ALA)enriched low-fat $(O)$ diets. Values are means, with standard deviations represented by vertical bars. Data were analysed using ANOVA for repeated measures. There is a diet effect $(P=0.205)$, a time effect $(P=0.242)$ and a time $\times$ diet interaction $(P=0.791)$. 


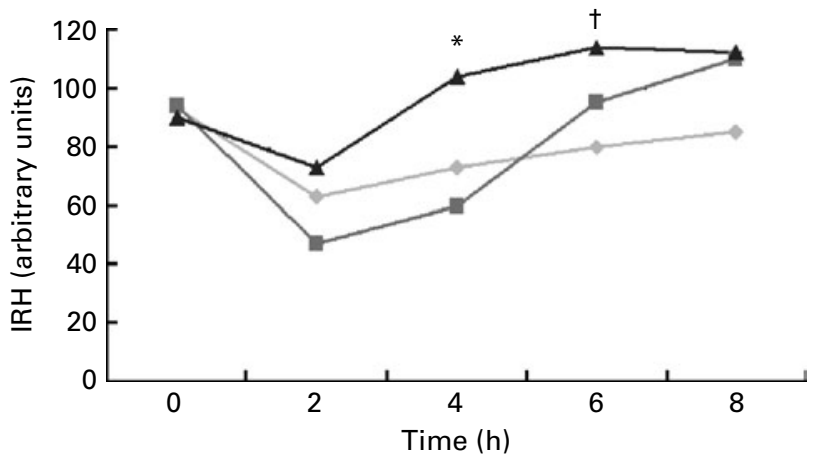

Fig. 3. Postprandial endothelial function (ischaemic reactive hyperaemia; IRH) studied by laser Doppler at the end of each dietary period: $(\diamond)$, SFA diet; $(\Delta)$, MUFA diet; $(\square) \alpha$-linolenic acid (ALA)-enriched low-fat diet. Values are means. Data were analysed using ANOVA for repeated measures. * Mean value for the MUFA diet is significantly different from those for the SFA diet and the ALA-enriched low-fat diet $(P<0.05)$. † Mean value for the MUFA diet is significantly different from that for the SFA diet $(P<0.05)$. There is a diet effect $(P=0.215)$, a time effect $(P=0.0001)$ and a time $\times$ diet interaction $(P=0.007)$.

a prolonged period of ingestion of a MUFA-rich diet than after the two other diets, and in turn the MUFA diet did not produce a postprandial decline in this vasodilatory response like that produced by the other diets. Similarly, the bioavailability of $\mathrm{NO}_{\mathrm{x}}$ was greater after chronic ingestion of the MUFA diet, possibly reflecting the positive influence of its lipid components on the activity of the endothelial NO synthase, as a sign of an improvement in the functionality of the endothelial cells. Moreover, $4 \mathrm{~h}$ after the MUFA meal, the bioavailability of $\mathrm{NO}_{\mathrm{x}}$ continued to be greater than after the ALA-enriched low-fat diet. This suggests that the MUFA diet has a beneficial effect on cardiovascular health, which may be due at least partly to its content of phenols, whose known vasodilatory and antioxidative effects characterise the virgin olive oil used in our diets ${ }^{(2)}$. Our data contrast with those of recent studies, such as Cortés et al. ${ }^{(3)}$, that did not find such effects, which were only observed after the ingestion of a meal rich in $n$-3 and not after a MUFA-rich meal, probably because the latter used non-virgin olive oil, whose phenolic content is only one-tenth of that of the virgin olive oil used in the present study and consumed in the Mediterranean diet.

Table 6. Correlations between diet and ischaemic reactive hyperaemia $(\mathrm{IRH})$ changes at different times

\begin{tabular}{lcc}
\hline IRH changes & $R$ & $P$ \\
\hline SFA diet & & \\
Baseline & 0.210 & 0.890 \\
4h & 0.198 & 0.687 \\
6 $\mathrm{h}$ & 0.099 & 0.952 \\
MUFA diet & & \\
Baseline & 0.411 & 0.042 \\
4 h & 0.439 & 0.021 \\
6h & 0.230 & 0.134 \\
ALA-enriched low-fat diet & & \\
Baseline & 0.111 & 0.202 \\
4 h & 0.624 & 0.753 \\
6h & 0.773 & 0.437 \\
\hline
\end{tabular}

ALA, $\alpha$-linolenic acid.
As well as IRH deterioration, endothelial dysfunction also involves a state of activation of the endothelium that is characterised by an increase in the expression and activation of inflammatory cytokines and leucocyte adhesion molecules ${ }^{(1)}$. Such endothelial activation is also influenced by what is ingested $^{(24)}$. Some studies have analysed the activation of the inflammatory endothelial response marked by sICAM-1 and sVCAM-1 after the acute ingestion of fat-rich meals. Tsai et al. ${ }^{(25)}$ did not find significant differences in levels of sICAM-1 or sVCAM-1 either before or after a meal rich in saturated fats and cholesterol. Other authors have found significant increases in these adhesion molecules, $4 \mathrm{~h}$ after similar meals ${ }^{(13)}$. We did not find differences in sICAM-1 levels following the fat-rich meal. However, the basal concentrations of sVCAM-1 after the MUFA and ALA-enriched low-fat diets were less than after the saturated fat period. In fact, adhesion molecule and endothelial activation is restored by $8 \mathrm{~h}$ after the meals. However, the transitory impairment of endothelial activation during the postprandial state probably leads to a higher risk of CVD if this state is sufficiently prolonged in time. In the postprandial study, the concentration of sVCAM- 1 at $4 \mathrm{~h}$ after the SFA meal remained higher, and the MUFA meal produced the lowest concentration of these inflammatory molecules. The SFA diet thus produced a basal endothelial activation similar to that described in inflammatory and chronic oxidative states such as arteriosclerosis and similar to those of other associated cardiovascular risk factors such as diabetes ${ }^{(8,26)}$. As far as the role of $n-3$ and adhesion molecules are concerned, sufficient evidence exists of a beneficial effect via the induction of a lower level of endothelial activation $^{(12)}$. However, in this study by Ros et al. ${ }^{(12)}$ these effects were obtained with $n-3$ as a supplement of a MUFArich Mediterranean diet that contains its own phytonutrients, making it difficult to evaluate the effects of $n-3$ itself on oxidative stress and endothelial activation, and on the improvement in endothelial-dependent vasodilatation, or, for that matter, whether the effects were produced by the other components of the MUFA-rich diet. These effects may in turn be related to a discrete fall in plasma cholesterol levels.

In conclusion, the chronic ingestion, over a period of 4 weeks, of a Mediterranean diet rich in virgin olive oil improves endothelial function in both fasting and postprandial states. Our findings indicate that chronic ingestion of this diet preserves endothelial-dependent vasodilatation during the postprandial state, thus hindering the development of arteriosclerosis.

\section{Acknowledgements}

We thank FIS for funding J. L.-M. (Instituto de Salud Carlos III no. 01/449), FIS for funding C. M. (Instituto de Salud Carlos III no. 04/1619), I + D for funding F. P.-J. (Ministerio de Educación y Ciencia no. SAF 2003-05 770) and I + D for funding J. L.-M. (Ministerio de Educación y Ciencia no. SAF 01/0366). The contribution of the authors was: F. F., J. L.-M., F. P.-J., for conception, design, analysis and interpretation of data, final approval; Y. J., P. G., C. M., P. P.-M., analysis and interpretation of data, drafting of the manuscript; J. M. F., J. C., J. D.-L., drafting of the manuscript and revising it critically for important intellectual content. There are no conflicts of interest. 


\section{References}

1. Hanson GK (2005) Inflammation, atherosclerosis, and coronary artery disease. $N$ Engl J Med 35, 1685-1695.

2. Ruano J, López-Miranda J, Fuentes F, Moreno JA, Bellido C, Pérez-Martínez P, Lozano A, Gomez P, Jimenez Y \& PerezJimenez F (2005) Phenolic content of virgin olive oil improves ischemic reactive hyperemia in hypercholesterolemic patients. J Am Coll Cardiol 46, 1864-1868.

3. Cortés B, Núñez I, Cofán M, Gilabert R, Pérez-Heras A, Casals E, Deulofeu R \& Ros E (2006) Acute effects of high-fat meals enriched with walnuts or olive oil on postprandial endothelial function. J Am Coll Cardiol 48, 1666-1671.

4. West SG (2001) Effect of diet on vascular reactivity: an emerging marker for vascular risk. Curr Atheroscler Rep 3, $446-455$.

5. Nettleton JA, Steffen LM, Mayer-Davis EJ, Jenny NS, Jiang R, Herrington DM \& Jacobs DR Jr (2006) Dietary patterns are associated with biochemical markers of inflammation and endothelial activation in the Multi-Ethnic Study of Atherosclerosis (MESA). Am J Clin Nutr 83, 1369-1379.

6. Lind L (2002) Lipids and endothelium-dependent vasodilation - a review. Lipids 37, 1-15.

7. Vogel RA, Corretti MC \& Plotnick GD (2000) The postprandial effect of components of the Mediterranean diet on endothelial function. J Am Coll Cardiol 36, 1455-1460.

8. Wang C, Harris WS, Chung M, Lichtenstein AH, Balk EM, Kupelnick B, Jordan HS \& Lau J (2006) n-3 Fatty acids from fish or fish-oil supplements, but not $\alpha$-linolenic acid, benefit cardiovascular disease outcomes in primary- and secondary-prevention studies: a systematic review. Am J Clin Nutr 84, 5-17.

9. Kris-Etherton PM, Harris WS \& Appel LJ (2002) Fish consumption, fish oil, omega-3 fatty acids, and cardiovascular disease. Circulation 106, 2747-2757.

10. Kristensen SD, Iversen AM \& Schmidt EB (2001) n-3 Polyunsaturated fatty acids and coronary thrombosis. Lipids 36, Suppl., S79-S82.

11. Brenna JT (2002) Efficiency of conversion of $\alpha$-linolenic acid to long chain n-3 fatty acids in man. Curr Opin Clin Nutr Metab Care 5, 127-132.

12. Ros E, Núñez I, Pérez-Heras A, Serra M, Gilabert R, Casals E \& Deulofeu R (2004) A walnut diet improves endothelial function in hypercholesterolemic subjects: a randomized crossover trial. Circulation 109, 1609-1614.

13. Nappo F, Esposito K, Cioffi M, Giugliano G, Molinari AM, Paolisso AM, Marfella R \& Giugliano D (2002) Postprandial endothelial activation in healthy subjects and in type 2 diabetic patients: role of fat and carbohydrate meals. J Am Coll Cardiol 39, 1145-1150.

14. Bellido C, López-Miranda J, Blanco-Colio LM, et al. (2004) Butter and walnuts, but not olive oil, elicit postprandial activation of nuclear transcription factor $\mathrm{kB}$ in peripheral blood mononuclear cells from healthy men. Am J Clin Nutr 80, 1487-1491.

15. Pérez-Martínez P, López-Miranda J, Blanco-Colio L, Bellido C, Jimenez Y, Moreno JA, Delgado-Lista J, Egido J \& Perez-Jimenez F (2007) The chronic intake of a Mediterranean diet enriched in virgin olive oil, decreases nuclear transcription factor $\kappa \mathrm{B}$ activation in peripheral blood mononuclear cells from healthy men. Atherosclerosis 194, e141-e146.

16. Wang XL, Zhang L, Keith Y, Zhang MX, Wang J, Le Marie SA, Coselli JS \& Shen YH (2006) Free fatty acids inhibit insulin signalling-stimulated endothelial nitric oxide synthase activation through upregulating PTEN of inhibiting Akt kinase. Diabetes 55, 2301-2310.

17. Human Nutrition Service Information Service \& Department of Agriculture Composition of Foods (1987) Agriculture Handbook, no. 8. Washington, DC: US Government Printing Office.

18. Varela G (1980) Tablas de Composición de Alimentos (Food Composition Tables). Madrid: Instituto de Nutrición CSIC.

19. Association of Official Analytical Chemists (1990) Official Methods of Analysis, 15th ed. Arlington, VA: AOAC.

20. Ruiz-Gutierrez V, Prada JL \& Perez-Jimenez F (1993) Determination of fatty acid and triacylglycerol composition of human very-low-density lipoproteins. J Chromatogr 22, 117-124.

21. Cooke JP (2004) The pivotal role of nitric oxide for vascular health. Can J Cardiol 20, Suppl., 7B-15B.

22. Plotnick GD, Corretti MC, Vogel RA, Hesslink R \& Wise JA (2003) Effect of supplemental phytonutrients on impairment of the flow-mediated brachial artery vasoactivity after a single high-fat meal. J Am Coll Cardiol 41, 1744-1749.

23. Sanderson P, Olthof M \& Grimble RF (2004) Dietary lipids and vascular function: UK Food Standards Agency workshop report. Br J Nutr 91, 491-500.

24. Burdge GC \& Calder PC (2005) Plasma cytokine response during the postprandial period: a potential causal process in vascular disease? Br J Nutr 93, 3-9.

25. Tsai WC, Li YH, Lin CC, Chao TH \& Chen JH (2004) Effect of oxidative stress on endothelial function after a high-fat meal. Clin Sci 106, 315-319.

26. Steiner M, Reihardt KM \& Krammer B (1994) Increased levels of soluble adhesion molecules in type 2 (non insulin dependent) diabetes mellitus are independent of glycaemic control. Thromb Haemost 72, 979-984. 